\title{
Problems with the finding of stochastic independence as evidence for multiple memory systems
}

\author{
ARTHUR P. SHIMAMURA \\ University of California, San Diego, California \\ (Larry R. Squire, Sponsor)
}

\begin{abstract}
Recently, the finding of stochastic independence has been used to infer that the processes underlying recognition memory and priming effects are independent. Stochastic independence between recognition memory and priming occurs if the probability of a word being primed is the same whether or not that word was correctly recognized. This inference, however, is invalid if the measure of recognition influences the measure of priming. If such influences occur, stochastic independence may be obtained even when two measures are dependent. This paper outlines some of the methodological problems associated with the stochastic-independence measure and offers some solutions.
\end{abstract}

Recently, there has been increased interest in stochastic independence as a way of assessing independence between two cognitive processes (see Tulving, 1985). In the past, the finding of stochastic independence has been used to argue that memory retrieval on one occasion is independent of memory retrieval on a second occasion (Flexser \& Tulving, 1978; Martin, 1971). Later, Hintzman (1980) voiced cogent arguments against the finding of stochastic independence as evidence for independent retrieval processes. Now, the finding has been used to claim that the processes underlying recognition memory and priming effects are independent and represent the workings of two different memory systems. In this article, I outline confounding variables that restrict the usefulness of stochastic independence as a way to dissociate recognition memory from priming ability.

Tulving, Schacter, and Stark (1982) were the first to argue that recognition memory and priming were stochastically independent. Subjects were presented words and, after a delay of $1 \mathrm{~h}$ or 7 days, were given tests of yes/no recognition memory $(\mathrm{Rn})$ and fragment completion (FC). In the fragment-completion (priming) test, subjects tried to form words from word fragments that could be completed to form previously presented words (e.g., AR _VA_ for AARDVARK). Tulving et al. (1982) found stochastic independence in that the joint probability of successful recognition and fragment completion was close to the simple probabilities of successful recognition and fragment completion [i.e., $p(R n \cap F C)=p(R n) p(F C)]$. Stated simply, the probabil-

I thank Larry Squire, Peter Graf, Daniel Schacter, and Thomas Nelson for helpful discussions of the issues presented in this paper. Request for reprints should be sent to A. P. Shimamura, Department of Psychiatry (116), Veterans Administation Medical Center, 3350 La Jolla Village Drive, San Diego, CA 92161. ity of completing a word fragment with a study word was the same whether or not that word had been correctly recognized on a preceding test.

This finding of stochastic independence suggested to Tulving et al. (1982) that the processes underlying these two measures operate independently of each other. Later, Tulving (1983) stated that "the finding of stochastic independence between recognition and fragment completion, therefore, constitutes additional independent evidence in support of the functional distinction between episodic and semantic memory"' (p. 105). The finding of stochastic independence since has been replicated and acknowledged by others as evidence of independence between recognition memory and priming (Eich, 1984; Light, Singh, \& Capps, in press; Witherspoon, as cited by Johnston, Dark, \& Jacoby, 1985).

There are, however, methodological problems with the measurement of stochastic independence. In order to assess stochastic independence between two memory tests, it is necessary to observe both outcomes concomitantly. For example, both recognition memory and priming must be tested at the same time, using the same items with the same subjects. Hintzman (1980, p. 400) noted, "As a practical matter, one cannot test the same subject repeatedly on the same item without changing the subject's state of knowledge." When a word-priming test precedes a recognition test, a bias occurs because the successful completion of a word in the priming test acts as a second study trial and boosts subsequent recognition performance. This effect produces a nonindependent result because the probability of correctly recognizing a word given a successful fragment-completion response is greater than the probability of correctly recognizing a word given a failure to complete the fragment. Two studies have reported this kind of bias (Shimamura \& Squire, 1984; Tulving et al., 1982). Thus, even if the processes that underlie recogni- 
tion memory and priming are independent, in these studies biases across tests prevented the finding of stochastic independence.

Thus, it has been acknowledged that, when a priming test precedes a recognition test, a fair test of stochastic independence cannot be achieved. However, when the order of tests are reversed so that a priming test follows a recognition test, the finding of independence has been considered valid. Yet, researchers seem to have ignored the possibility that a priming test can be affected by a preceding recognition test, just as a recognition test is affected by a preceding priming test. The mere presentation of study words in a yes/no recognition test, regardless of whether the words are correctly recognized, facilitates subsequent fragment completion performance. In one study, for example, this priming effect-called test priming-boosted completion performance to $65 \%$, compared to $46 \%$ completion performance when the recognition test did not precede the priming test (Tulving et al., 1982). Because priming from the recognition test boosted completion performance independently of performance in the recognition test, any relationship (dependence) that may have existed between the processes of recognition and priming may be reduced. If substantial priming occurs as a result of word presentation during the recognition test, the finding of stochastic independence is not valid evidence for independence between priming and recognition memory.

The following hypothetical experiment illustrates the extent to which intertest biases can influence the measure of stochastic independence. Suppose that 100 words are presented, and subjects are first given a yes/no recognition test and then a fragment completion test. The simple probability of recognition is set at .60 , and the simple probability of completion without the influence of a preceding recognition test is set at 46 . (These probabilities are similar to those obtained by Tulving et al., 1982.) Also, suppose that there is dependence between recognition memory and priming such that the probability of successful fragment completion given successful recognition is large $[\mathrm{p}(\mathrm{FC} \mid \mathrm{Rn})=.57]$ relative to the probability of successful fragment completion given recognition failure $[\mathrm{p}(\mathrm{FC} \mid-\mathrm{Rn})=.30]$. The contingency table in Table 1 shows the pattern of results when no intertest biases occur. Stochastic independence can be rejected $\left(\chi^{2}=6.9\right.$, $\mathrm{p}<.01)$.

I now introduce a bias that increases the probability of fragment completion regardless of recognition performance. This bias mimics the "test-priming" effect that

Table 1

Initial Positive Relationship Between Fragment-Completion Performance (FC) and Recognition-Memory Performance (Rn)

\begin{tabular}{rccc}
\hline & $\mathrm{Rn}$ & $-\mathrm{Rn}$ & Marginals \\
\hline $\mathrm{FC}$ & 34 & 12 & 46 \\
$-\mathrm{FC}$ & 26 & 28 & 54 \\
Marginals & 60 & 40 & 100 \\
\hline Note $-p(F C \mid R n)=.57 ; p(F C \mid-R n)=.30 ; \chi^{2}=6.9, p<.01$.
\end{tabular}

Table 2

The Effect of "Test Priming" Gives the Appearance of Stochastic Independence

\begin{tabular}{rrrc}
\hline & $\mathrm{Rn}$ & $-\mathrm{Rn}$ & Marginals \\
\hline FC & 47 & 26 & 73 \\
$-\mathrm{FC}$ & 13 & 14 & 27 \\
Marginals & 60 & 40 & 100 \\
\hline
\end{tabular}

Note-Here, completion performance has been raised by increasing completion of previously noncompleted items by a factor of.50. $p(F C \mid R n)=$ $.78 ; p(F C \mid-R n)=.65 ; \chi^{2}=2.1, p>.1$.

a preceding recognition test would have on fragment completion. This test-priming bias is set at .50; that is, $50 \%$ of previously uncompleted words would be completed as a result of a preceding recognition test. ${ }^{1}$ The contingency table in Table 2 shows the effect of test priming. The probability of priming is increased to .73 . Moreover, this effect reduced the initial relationship between recognition and fragment completion [now $\mathrm{p}(\mathrm{FC} \mid \mathrm{Rn})=.78$ and $\mathrm{p}(\mathrm{FC} \mid-\mathrm{Rn})=.65$ ]. In fact, the chi-square analysis now supports stochastic independence $\left(\chi^{2}=2.1, \mathrm{p}>.1\right)$.

This example illustrates how a strong dependence between two measures can be dramatically reduced by test priming. The test-priming factor need not be as high as .50 in order to reduce a dependence between two measures. Even if test priming biased the results by a factor of only .30 instead of .50 , the finding would still be biased in favor of stochastic independence $\left(\chi^{2}=3.5\right.$, $p>.05]$. In fact, given a test priming factor of at least .30 and simple probabilities of .46 and .60 for fragment completion and recognition memory, respectively, any dependent relationship with a chi-square significance at the .01 level or less would be biased in favor of stochastic independence $(p>.05)$. It should be noted, however, that these calculations do not prove that recognition and priming were associated in previous studies that have claimed independence. They do suggest that the finding of stochastic independence cannot establish independence between cognitive processes. When intertest biases are present, the findings are equivocal.

To summarize, when a priming test precedes a recognition test, intertest biases can produce a relationship between priming and recognition, even if one did not exist before testing. When a recognition test precedes a priming test, intertest biases can reduce any initial dependence that may have existed. A similar bias can be shown for free recall when recall is tested before word completion. Graf, Shimamura, and Squire (1985) found that the probability of word completion was higher after successful recall than after unsuccessful recall of a study word. In this case, the act of recalling an item could have facilitated word completion, but this facilitation would benefit only correctly recalled words. Unlike the case in which a preceding recognition test biased the results in favor of stochastic independence, a preceding recall test biased the results in favor of a positive relationship between recall and priming, even if one had not existed prior to testing.

With careful attention to these biases, however, stochastic independence can be a useful technique for making 
statements about the interdependency of cognitive processes. First, it may be possible to show that for one condition of an independent variable, there is a greater association between two dependent measures than for another condition. For example, Witherspoon (as cited by Johnston et al., 1985) showed that words produced an observed stochastic independence between recognition memory and fragment completion, whereas nonwords failed to produce stochastic independence. Based on the arguments presented here, the claim of stochastic independence for words is not valid because the recognition test would prime study words regardless of recognition performance, and this effect could conceal a relationship between the two measures. If, however, the relationship between recognition and priming were reliably greater for nonwords than for words, and if the amount of test priming were similar across conditions, then it is reasonable to suppose that the processes that underlie the two measures are more strongly associated for nonwords than for words.

A second and stronger way to establish stochastic independence between cognitive processes is to prevent any intertest biases. For example, Eich (1984) presented related word pairs to the unattended ear in a dichotic listening task. The critical words were homophones that would be disambiguated by the words that were paired with them (e.g., BARTLETT-PEAR). At test, subjects were given first a recognition test and then a priming test in which subjects spelled previously presented homophones. There were no intertest influences, however, because the recognition test was given verbally so that no additional cues to the spelling of the words were given during the recognition test. Eich (1984) found stochastic independence between tests of recognition memory and priming. Unfortunately, in this particular experiment, recognition memory was at chance levels, and thus floor effects may have concealed an actual dependence between the two measures. Nevertheless, the study by Eich (1984) demonstrates that it is possible to construct experiments in which there are no intertest biases.

In conclusion, measures of stochastic independence are sensitive to intertest biases. Previous findings of stochastic independence could have been influenced by these biases.
Depending on how tests influence one another, one can wrongly infer independence or dependence between cognitive processes. In order to apply this measure to identify independent cognitive processes, it is necessary to construct tests such that (1) performance on the first test does not influence performance on the second, or (2) the direction of bias is known so that it can be discounted as a factor.

\section{REFERENCES}

EICH, E. (1984). Memory for unattended events: Remembering with and without awareness. Memory \& Cognition, 12, 105-111.

FleXser, A. J., \& TUlviNG, E. (1978). Retrieval independence in recognition and recall. Psychological Review, 85, 153-171.

Graf, P., Shimamura, A. P., \& SQuire, L. R. (1985). Priming across modalities and priming across category levels: Extending the domain of preserved function in amnesia. Journal of Experimental Psychology: Learning, Memory, \& Cognition, 11, 385-395.

HINTZMAN, D. L. (1980). Simpson's paradox and the analysis of memory retrieval. Psychological Review, 87, 398-410.

Johnston, W. A., DARK, V. J., \& JACOBY, L. L. (1985). Perceptual fluency and recognition judgments. Journal of Experimental Psychology: Learning, Memory, \& Cognition, 11, 3-11.

Light, L. L., Singh, A., \& CAPPS, J. L. (in press). The dissociation of memory and awareness in young and older adults. Journal of Clinical and Experimental Neuropsychology.

MARTIN, E. (1971). Verbal learning theory and independent retrieval phenomena. Psychological Review, 78, 314-332.

Shimamura, A. P., \& SQUiRe, L. R. (1984). Paired-associate learning and priming effects in amnesia: A neuropsychological study. Journal of Experimental Psychology: General, 113, 556-570.

Tulving, E. (1983). Elements of episodic memory. New York: Oxford University Press.

Tulving, E. (1985). How many memory systems are there? American Psychologist, 40, 385-398.

Tulving, E., Schacter, D., \& Stark, H. A. (1982). Priming effects in word-fragment completion are independent of recognition memory. Journal of Experimental Psychology: Learning, Memory, \& Cognition, 8, 352-373.

\section{NOTE}

1. It is not possible to determine exactly the degree of test priming in previous experiments. However, the amount of test priming (TP) in the Tulving et al. (1982) study was at most .54, the amount of priming due to testing alone. If this score is corrected for guessing probability $(\mathrm{g}=.30)$, then the test priming bias, $\mathrm{p}(\mathrm{B})$, can be estimated at .34 by solving for $p(B)$ in the following equation: $p(T P)=g+(1-g) p(B)$.

(Manuscript received for publication June 21, 1985.) 